\title{
Retos y propuestas para una educación para la ciudadanía a partir de una noción compleja e intercultural de derechos humanos
}

\author{
David Sánchez Rubio ${ }^{1}$
}

Resumen: En este trabajo se denuncia el paradigma generalizado que sobre los derechos humanos existe a nivel internacional y nacional por ser excesivamente estrecho y reducido. Este mismo paradigma se refleja en las políticas educativas en materia de ciudadanía y derechos humanos. Como propuesta se ofrece una perspectiva compleja y relacional que de cuenta de algunas de las razones que hay por el abismo entre la teoría y la práctica de los derechos humanos. Finalmente se ofrece una lectura educativa en clave intercultural que de cuenta de la diversidad humana y sus distintas versiones de dignidad.

Palabras Claves: Derechos humanos. Educación cívica. Interculturalidad. Multiculturalismo. Luchas sociales. Garantías jurídicas. Eficacia. Sensibilidad sociocultural.

\begin{abstract}
The aim of this paper is to render the current paradigm regarding human rights both excessively reduced and narrow. The same paradigm applies within educational policies concerning citizenship and human rights. A complex and relational perspective is proposed as an attempt to offer sound explanations of the abyss detected between theory and practice in the human rights area. Finally, a multicultural and educational approach is employed as a tool to describe human diversity and its different versions of dignity.
\end{abstract}

Keywords: Human rights. Multiculturalism. Interculturalism. Social struggels. Civic education. Legal guarantees. Efficacy. sociocultural sensitivity

\section{Introducción}

La vida social requiere de un conjunto de normas, reglas, instituciones y procedimientos que regulen la convivencia humana. Todas

1 David Sánchez Rubio, Profesor Titular de Filosofía del Derecho. Facultad de Derecho. Universidad de Sevilla. Autor de diversos libros entre los que destacan Filosofía, derecho y liberación en América Latina (1999); Repensar derechos humanos. De la anestesia a la sinestesia (2007); y El pensamiento humanista de Leopoldo Zea. Conciencia histórica y derechos humanos, (2008). Especialista en teoría crítica del Derecho, derechos humanos y pensamiento de liberación. 
ellas son necesarias para canalizar las relaciones entre sus miembros. Resulta muy difícil imaginar una sociedad en donde no existan valores y normas éticas, morales o jurídicas que señalen el tipo de conductas que se deben y/o no se deben realizar. Tampoco es posible pensar, hoy en día, que haya algún modo social de vida que funcione sin ningún tipo de institución ya sea de carácter político, religioso, económico o jurídico como puede ser el mercado, el Estado, el Derecho o las asociaciones y agrupaciones colectivas (clubes deportivos, comunidades, empresas, iglesias, $\mathrm{ONG}$, centros educativos, etc.). Quizá en un pasado muy remoto se pudiera vivir sin ellas, pero esto no sucede en nuestro presente. Las relaciones humanas necesitan ser reguladas por ciertos instrumentos $\mathrm{y}$ medios que las organicen, que les proporcionen cierto orden y seguridad, porque si no existen, se desarrollarían caóticamente y en un clima de permanente incertidumbre y desasosiego.

En este trabajo, indirectamente, se hablará de aquellas reglas de juego, del conjunto de responsabilidades, derechos y obligaciones, valores, acciones y prácticas que debemos conocer, asumir, cumplir y desarrollar para vivir con justicia, libertad, igualdad, paz, solidaridad y en democracia a partir de la figura de los derechos humanos. No obstante, se hará proponiendo una manera diferente de entender lo que tradicionalmente se concibe como derechos humanos. Cuando se reivindica para los sistemas educativos de secundaria, bachillerato y universitarios la incorporación de la enseñanza ético-cívica en base a la democracia y los derechos humanos, no basta limitarnos a dar por sentados conceptos que pueden tener una fuerte carga ideológica y que, además, pueden servir para fortalecer todo lo contrario de lo que supuestamente nos transmiten: una participación ciudadana activa, comprometida que convive solidariamente en el respeto efectivo de los derechos de sus miembros. Por ello, también hay que conocer bien cuál es la idea que defendemos y tenemos de estos conceptos. A continuación nos detendremos en los derechos humanos, para después terminar intentando dar algunas pistas de cómo interpretarlos a partir de una noción compleja y relacional, con algunas claves interculturales. 


\section{La importancia y el reto de los derechos humanos en un mundo adverso}

Dentro de nuestro imaginario cultural occidental, el pensamiento moderno, principalmente a través de los filósofos contractualistas del iluminismo, ya reflexionó sobre la importancia de establecer un contrato social a partir del cual, todos los ciudadano obedecieran un conjunto de reglas y valores acordados por todos. Todos ellos debían aceptar someterse a una institución, el Estado, que estaba legitimado para ejercer el poder y realizar el uso de la fuerza de manera delegada y representativa. De esta manera, se pretendía compaginar, consensualmente, la libertad y la autonomía de cada individuo con el bien común y el interés general. Hombres como Thomas Hobbes, John Locke y Jean Jacques Rousseau, desde posiciones distintas, se preocuparon por establecer las condiciones de un sistema de gobierno que se responsabilizara de proteger los derechos de sus miembros. Las ideas de libertad, igualdad, solidaridad y seguridad aparecían como los principales valores que se debían proporcionar y facilitar. Se intentaba armonizar la dimensión individual y la dimensión colectiva del ser humano; sus derechos con sus deberes. Para poder llevar esto a cabo, tanto la democracia como los derechos humanos resultaron ser conceptos imprescindibles para la vida en sociedad.

Actualmente, los Estados constitucionales y democráticos de Derecho se asientan sobre ese mismo imaginario moderno: nuestras sociedades se rigen por normas (constituciones, leyes y reglamentos) aceptadas por todos y destinadas a regular el bien común. Asimismo, indican quiénes son los agentes legitimados tanto para crearlas como para ejercer legalmente el poder, cómo llevarlo a cabo, y sobre qué materias o contenidos. Dentro de ese margen, también nos señalan el procedimiento a seguir para que nuestros derechos estén protegidos o, en su caso, sean resarcidos cuando son violados. De nuevo se intenta construir un marco de convivencia social y en el que la libertad y la autonomía de las personas sean compatibles con el bien común de todos, en un clima abierto a los demás y de no violencia y respeto.

En el contexto latinoamericano, nos encontramos con muchos estados que incorporan esta misma lógica y esquema garantista europeo 
y usamericano. Pero curiosamente, algunos de los países de capitalismo tardío que adoptan esta estructura jurídico-política como Bolivia, Ecuador y Venezuela, bajo el llamado nuevo constitucionalismo y autodenominándose como estados plurinacionales - con cierta afinidad pero con diferente perspectiva política Brasil también constitucionaliza derechos étnicos y colectivos -, están reconociendo una serie de nuevos derechos vinculados con la dimensión multiétnica y plurinacional de sus sociedades. Se trata de un proceso de mestizaje cultural en el que el paradigma moderno no es el único que establece las condiciones de garantía jurídico-política. A él se suman otras racionalidades y otras epistemologías tradicionalmente silenciadas y marginadas que reclaman su reconocimiento. Esos derechos suelen ser de carácter colectivo relacionados con los pueblos indígenas y/o grupos afrodescendientes (p.e. el derecho a la tierra, el derecho a la autodeterminación y la autonomía, derechos culturales - educación, idioma, usos y costumbres. -, etc.) y sistemáticamente negados a lo largo de una trágica historia de resistencia, expolio, genocidio y barbarie. Asimismo, este nuevo constitucionalismo incorpora en sus cartas magnas derechos ambientales que protegen la biodiversidad y el medioambiente, también muy vinculados con las culturas milenarias. Por ejemplo, en este sentido, la Constitución ecuatoriana parte de que la Naturaleza es sujeto de derechos y como tal debe ser garantizada, protegida y cuidada.

El caso es que estos instrumentos de garantía y de organización político-jurídica contrastan, en general, con el contexto global en el que vivimos y, en especial, con el contexto particular latinoamericano: las guerras; la contaminación medioambiental y de la naturaleza; la proliferación y la amenaza provocada por el armamento nuclear; las desigualdades sociales y el incremento de la pobreza a nivel planetario; las consecuencias y los riesgos de los avances tecnológicos; distintas manifestaciones de discriminación, violencia y exclusión social, étnica, racial o de género; el problema del narcotráfico; el trabajo esclavo; la prostitución; la corrupción; etc., son elementos negativos que impiden a los seres humanos vivir dignamente, en un clima de felicidad y justicia. Muchas son las personas que sufren todos los días condiciones infrahumanas y execrables de existencia. Los actuales procesos de globalización han cambiado radicalmente el contexto que existía hace 
unos años. El mundo está cada vez más interconectado, para bien o para mal, y los intercambios culturales, sociales, políticos y económicos se han incrementado a un ritmo vertiginoso. Recibimos información de cualquier parte del planeta y, en un concreto espacio geográfico, conviven personas de diversa procedencia y con culturas y formas de vida diferentes. Las relaciones humanas se hacen más complejas y los mecanismos para su regulación también.

Además, cada día se incrementan los procesos migratorios por medio de los cuales, millones de personas se desplazan de un país a otro, produciendo conflictos y mutaciones en las identidades tanto de los grupos que emigran como de la población residente que los recibe. En estos caminos de ida y, a veces, de vuelta también surgen conflictos generacionales que hacen más compleja y difícil la convivencia humana y el respeto por la diferencia.

Por lo tanto, por un lado nos encontramos con un panorama desolador que no debe llevarnos hacia el pesimismo. Pero, por otro lado, también nos situamos en un nuevo escenario esperanzador que promete muchas posibilidades y opciones. En todo esto, bastante tienen que decir los derechos humanos, la ciudadanía y los comportamientos democráticos. Todos ellos representan figuras, conceptos y prácticas que son imprescindibles y necesarias en nuestra vida diaria, porque sirven para enfrentar las situaciones injustas de las sociedades modernas. Asimismo, son muy útiles para construir realidades donde los seres humanos puedan ser más libres, puedan tener sus condiciones de vida más garantizadas y puedan obtener, de manera más plena, la satisfacción de sus necesidades básicas. Proporcionan tanto los medios como los mecanismos que nos permiten enfrentar mejor cualquier tipo de injusticia social, al menos, en principio.

\section{La educación en derechos humanos: condicionantes y límites de una idea restringida}

En los últimos años, este horizonte de esperanza se ha manifestado por el interés de la comunidad internacional y de muchos Estados de Derecho por la educación ciudadana y la educación en derechos humanos. 
En todas las agendas gubernativas están ganando protagonismo como una de las principales vías por medio de la cual se abra una cierta salida hacia un mundo más justo y solidario. En el caso de España tenemos un ejemplo con la asignatura de secundaria denominada Educación para la ciudadanía y los derechos humanos establecida por el gobierno de Rodríguez Zapatero, como respuesta a las directrices marcadas desde la Unión Europea, a pesar de la polémica que ha generado. ${ }^{2}$ También, desde el gobierno de Fernando Henrique Cardoso en Brasil, la Secretaría Especial de los Derechos Humanos dela Presidencia de la República está desarrollando un Plan Nacional de Derechos Humanos. ${ }^{3} \mathrm{Y}$ en otros países como Ecuador, al interés por la educación en derechos humanos se añade la promoción de la educación intercultural bilingüe con el Modelo del Sistema de Educación Intercultural Bilingüe de 1998 y el Rediseño Curricular para los centros educativos comunitarios interculturales bilingües de la Nacionalidad Kichwa de la Región Andina del año 2004. ${ }^{4}$ Educar en derechos humanos se está convirtiendo en una exigencia necesaria y prioritaria. Suena bien que los gobiernos hablen de derechos humanos e implementen políticas educativas, promocionándolos, pero ¿se está realizando de la mejor manera? Es más, ¿realmente se están enfocando correctamente estas políticas en función de la idea de derechos humanos desde la que se parte y que hay que enseñar?

Desde nuestro punto de vista, la educación en derechos humanos, tanto en el ámbito internacional, como en el ámbito más regional como es el europeo y el latinoamericano, parte de una noción demasiado estrecha, reducida, restringida y, además, eurocéntrica. ¿Por qué decimos esto?

Por lo general, resulta típico, tópico y clásico dar por sentada la separación que existe entre lo que se dice y lo que se hace en materia de

2 En este sentido, ver Gregorio Peces Barba, Educación para la ciudadanía y derechos humanos, Espasa, Madrid, 2007. Un ejemplo de manual de la asignatura, David Sánchez Rubio (coord.), Educación para la ciudadanía y derechos humanos, Algaida, Sevilla, 2007.

3 Recientemente con Ignacio Lula da Silva se publicó el III Plan. Ver el Decreto $n^{\circ} 7.037$ de 21 de diciembre de 2009, www.sedh.gov.br.

4 Ver Marcelo Quishpe Bolaños, "Educación e interculturalidad en los pueblos indígenas de la sierra ecuatoriana”, en Diana Carrillo González y Nelson Santiago Patarroyo (edit.), Derecho, interculturalidad y resistencia étnica, Universidad Nacional de Colombia, 2009. 
derechos humanos. Casi todo el mundo tiene metida en la cabeza la idea de que es muy diferente la teoría y la práctica sobre derechos humanos. Este abismo se considera indiscutible y muy difícil de superar. Mucho se ha escrito y se ha dicho sobre las posibles causas de este distanciamiento, pero pocos son los estudios y las políticas educativas que parten de la premisa de que quizá esta separación entre lo dicho y lo hecho, entre el plano del ser y del deber ser resida en nuestra propia manera de pensar derechos humanos. A lo mejor es que bajo una cultura interesadamente conformista, indolente, acomodaticia, pasiva y hegemónica conviene entender derechos humanos a partir de estos dos planos aparentemente tan distintos. Parece como si existiera una cultura de impotencia que, bajo la excusa de ese abismo entre lo dicho y lo hecho, adopta la actitud de seguir dejando las cosas tal como están. Posiblemente nos conviene mantener esta diferencia para consolidar y reforzar una cultura de derechos humanos demasiado estrecha, reducida y simplista que tanto en la superficie como en el fondo conviene a quienes, realmente, prefieren convivir incumpliendo, destruyendo y/o ignorando derechos humanos.

El caso es que esta misma idea tan limitada se está incorporando en los programas de enseñanza en materia de educación cívica y de derechos humanos. Bajo una aparente buena fe e intención para que los ciudadanos aprendan a convivir cívicamente, se están usando unos conceptos que parten de un imaginario y una epistemología demasiado simplista sobre derechos humanos que termina por potenciar una cultura cívica dócil, pasiva y estática. Incluso yendo más allá, institucionalmente tanto a nivel de secundaria como universitario se nos enseña una noción tan restringida y tan reducida de derechos humanos que, al final, acaba por desempoderar a todos los seres humanos, porque con esa concepción oficializada y extendida no se nos reconoce realmente en nuestra capacidad de dotar de carácter a nuestras propias producciones culturales, políticas, étnicas, sexuales-libidinales, económicas y jurídicas con autonomía, responsabilidad y autoestima en todos aquellos espacios y lugares sociales en los que se forjan las mismas relaciones humanas. Parece como si derechos humanos fuese únicamente un problema de adquirir conocimientos sobre las normas, las leyes, las instituciones y sus mecanismos de garantía. Los resultados saltan a la vista: se fomenta una cultura cívica débil, frágil y puntual. 
La situación se agrava en contextos, como el latinoamericano, en los que el fascismo social está estructuralmente establecido en sus sociedades, con altos índices de desigualdad social, racismo, xenofobia, machismo y violencia. En estos contextos hay una total ausencia de cultura de derechos humanos que se maquilla con formalismos y procedimentalismos vacíos. Reclamar su presencia es necesario, pero hacerlo a partir de un imaginario simplificador, puede resultar fútil, inútil y/o con resultados azarosamente puntuales.

Esta separación entre la teoría y la práctica que damos como natural e indiscutible es una de las razones que justifican la indolencia y la pasividad a la hora de construir y enseñar día a día y en todos los lugares sociales, derechos humanos: en las escuelas, en los centros cívicos, en la universidad, en los barrios vecinales, en las fuerzas policiales y militares, etc.. Por mucho que se enseñe derechos humanos, los resultados incitan al pesimismo. Seguro que ahí está la trampa: al considerarse como natural, normal e indiscutible la distancia entre lo practicado y lo hablado, se está consolidando y fortaleciendo una forma de entender y practicar la convivencia humana sin más pretensiones, que interesa a quienes más les beneficia que eso sea así. Pues bien, creemos que esta es la misma concepción que aparecen en los distintos programas de enseñanza sobre educación cívica y en derechos humanos que se están desarrollando tanto en Europa como en América Latina.

Asimismo, la gravedad del asunto se incrementa porque la poca cultura que existe sobre derechos humanos, que es excesivamente formalista, resulta ser tan extremadamente reducida, insuficiente $\mathrm{y}$ estrecha que, de manera voluntaria y/o involuntaria, termina por reforzar y hacer hegemónica esa separación entre lo que se dice y lo que se hace en materia de derechos humanos. Por esta razón, se hace necesario señalar algunas pistas para articular y defender una concepción mucho más compleja, relacional, socio-histórica y holística que priorice las propias prácticas humanas y a los sujetos que las significan. Estos, a partir de sus relaciones, son quienes realmente hacen y deshacen, construyen y destruyen derechos humanos y sobre sus prácticas se inspiran y elaboran las teorías y las diversas políticas de enseñanza cívica. Esto es lo que intentaremos realizar a continuación. 


\section{Hacia una concepción compleja de derechos humanos: una propuesta para los programas de educación cívica}

Generalmente, cuando se habla de derechos humanos se suele acudir a una idea de los mismos basada en las normas jurídicas, en las instituciones con el Estado a la cabeza y en ciertos valores que le dan fundamento (como la libertad, la igualdad y la solidaridad) y que están o bien basados en la misma condición humana o bien reflejados en sus producciones normativas e institucionales. Derechos humanos son aquellos derechos reconocidos tanto en el ámbito internacional como nacional, por las constituciones, normas fundamentales, cartas magnas, tratados y declaraciones basadas en valores. Resulta muy útil y positivo enseñar en las escuelas y en los centros educativos cuáles son esas normas nacionales e internacionales.

Esto, consciente e inconscientemente, conlleva varias implicaciones o consecuencias que vamos a resaltar a partir de los planteamientos del chileno y analista político, Helio Gallardo. Para este autor, derechos humanos hacen referencia, al menos, a cinco elementos: a) la lucha social; b) la reflexión filosófica o dimensión teórica y doctrinal; c) el reconocimiento jurídico-positivo e institucional; d) la eficacia y efectividad jurídica; y e) la sensibilidad sociocultural. ${ }^{5}$

Si observamos los currículo y la normativa sobre la educación cívica y en derechos humanos, percibiremos de qué manera, partir de estos distintos elementos, nuestro imaginario oficial y más difundido solo se fija en alguno de ellos, invisibilizando al resto. Se suele supervisibilizar

\footnotetext{
5 Ver sus libros Politica y transformación social. Discusión sobre derechos humanos, Editorial Tierra Nueva, Quito, 2000; Siglo XXI: militar en la izquierda, Arlekín, San José, 2005; Siglo XXI: producir un mundo, Arlekín, San José, 2006; y Derechos humanos como movimiento social, Ediciones desde abajo, Bogotá, 2006.

El concepto de derechos humanos entendido en perspectiva crítica y concebidos como "procesos de apertura y consolidación de espacios de lucha por la dignidad humana" en gran parte se lo debemos a Joaquín Herrera Flores, recientemente fallecido y cuya huella difícilmente será borrada. Ver sus trabajos en El vuelo de Anteo, Desclée de Brouwer, Bilbao, 2000; y Los derechos humanos como productos culturales. Crítica del humanismo abstracto, Los Libros de la Catarata, Madrid, 2005.
} 
la dimensión normativa e institucional; la dimensión teórico-filosófica y la eficacia jurídico-estatal. En España, casi todos los libros de Educación en ciudadanía y derechos humanos así lo hacen. Se se silencia, no se considera o se da escasa importancia a ámbitos fundamentales como la lucha social (que cuando se reconoce se hace de manera muy puntual), la eficacia no jurídica y la eficacia jurídica no estatal, así como la cultura y sensibilidad popular, que son básicos para poder entenderlos mejor y ponerlos más coherentemente en práctica. Desde nuestro punto de vista, estos insumos infravalorados nos pueden permitir superara y/o enfrentar esa separación que sistemáticamente existe entre lo que se dice y lo que se hace sobre derechos humanos y que impiden desarrollarnos como sujetos y autónomamente. Por ello son elementos que deberían incorporarse en los programas de enseñanza y de educación en ciudadanía y en derechos humanos.

Con respecto a los elementos supervalorados o que siendo parte de una estructura más compleja, se convierten en el todo ignorando al resto, hay que decir lo siguiente:

- Comúnmente y desde un plano teórico, los derechos humanos suelen asociarse y conocerse por lo que, a lo largo de la historia, nos han dicho y nos dicen determinados pensadores o filósofos. Autores como John Locke, Francisco de Vitoria, Rousseau, Hobbes, Kant, Norberto Bobbio, Ferrajoli, Habermas, son algunos de las mentes lúcidas que han hablado sobre derechos humanos. El problema radica no en las iluminadoras reflexiones que sobre los mismos nos aportan sino en pensar que son ellos, los filósofos o especialistas, quienes los crean, olvidando el detalle de que derechos humanos son producciones socio-históricas generadas por actores sociales sobre las que y sobre quienes se teoriza.

En América Latina suele ser común enseñar en las Facultades de Filosofía y de Derecho las teorías y los sistemas filosóficos desarrollados en los países anglosajones y en Europa. No es que las ideas europeas y anglosajonas sean malas y negativas. Lo que sí resulta perjudicial es que, por sistema, se tiene la manía de importar en bloque, sin adaptarlos, modelos políticos y filosóficos nacidos en realidades diferentes a las realidades de los países latinoamericanos. Por falta de autoestima o por 
una especie de complejo de inferioridad, se suelen importan ideas que han sido elaborados para contextos diferentes y se olvida la capacidad creativa e imaginativa de los propios latinoamericanos en su pluralidad de expresiones. Conocida es el reclamo del cubano José Martí a finales del siglo XIX en "Nuestra América" sobre la necesidad de que América Latina desarrollara un conocimiento ubicado y propio que atendiera a las necesidades particulares de sus repúblicas. En este sentido, también el filósofo mexicano Leopoldo Zea ha defendido la urgencia de un pensamiento político, fílosófico y jurídico autóctono, sin rechazar las fuentes europeas y anglosajonas. ${ }^{6}$

Asimismo, tal como ya se ha señalado, una faceta importante de los derechos humanos es su proceso de institucionalización $\mathrm{y}$ reconocimiento normativo tanto a escala nacional como internacional. Cuando movimientos sociales como el de la burguesía en el proceso de conformación de las sociedades modernas, o como el movimiento obrero en el siglo XIX y los movimientos de las mujeres y los indígenas en el siglo XX con sus antecedentes en el pasado, se levantaron para reivindicar mayores espacios de libertad y denunciar distintas formas de exceso del poder (económico, cultural, étnico, libidinal, etc.), el objetivo del reconocimiento constitucional y jurídico se hizo crucial para objetivar sus demandas. De ahí la importancia que tiene la dimensión jurídicopositiva de los derechos humanos, pero el darle excesiva importancia provoca, como veremos, una eficacia minimalista, reducida e insuficiente con relación al número de violaciones que todos los días suceden en el mundo - particularmente en América Latina -, y el tipo de garantías procedimentales que se establecen como respuesta.

- Además, junto con el reconocimiento normativo, la eficacia y la efectividad jurídica de derechos humanos suele ser el principal recurso al que se acude para garantizarlos. Que haya tribunales de

\footnotetext{
6 Ver José Martí, Obras Completas, Editorial Nacional de Cuba, La Habana, 1963. Sobre Leopoldo Zea, sus Dialéctica de la conciencia americana, Alianza Editorial Mexicana, México D. F., 1974 y El pensamiento latinoamericano, Ariel, México D. F., 1976; ver también David Sánchez Rubio, El pensamiento humanista de Leopoldo Zea. Conciencia histórica y derechos humanos, Comisión Estatal de Derechos Humanos de San Luis Potosí y Facultad de Derecho de la Universidad Autónoma de San Luis Potosí, 2008.
} 
justicia a los que acudir para denunciar y estados de Derecho para que los derechos fundamentales sean protegidos no es algo que haya que despreciar, todo lo contrario. Pero centrar nuestro imaginario solo en estos tres elementos, sobredimensionándolos, tiene efectos dañinos para la mayoría de la humanidad. Para demostrar lo que estamos diciendo, solo tenemos que fijarnos en este ejercicio de reflexión: ¿cuántas violaciones de derechos humanos suceden todos los días en el mundo o en los estados que se dicen de derecho? Seguro que muchísimas, incalculables. ¿Cuántas de esas violaciones son atendidas judicialmente, con sentencia favorable y además efectiva? Seguro que siendo generosos, la proporcionalidad es de un $99,9999 \%$ de violaciones y un $0,0001 \%$. Por tanto algo pasa cuando nuestro imaginario camina por paisajes tan pequeños. Si se observa bien, resulta curioso comprobar que circunscribimos derechos humanos a una simple reivindicación o demanda judicial interpuesta ante los tribunales de justicia, una vez que los mismos han sido violados. Luego solemos defender una concepción posviolatoria de derechos humanos ignorando o haciendo poco caso a la dimensión pre-violatoria. Derechos humanos parecen que solo existen una vez que han sido violados, no importándonos aquella dimensión de su realidad que se construye o se destruye antes de acudir al Estado.

- Asimismo, el hecho de que derechos humanos se reduzcan a normas, instituciones y teorías, provoca una especie de delegación del conjunto de los mortales que se centra en el protagonismo adjudicado a los funcionarios de la administración de cada Estado y a los especialistas encargados de interpretar las normas. Como mucho, también se suele acudir a los activistas de derechos humanos que actúan la mayoría de las veces, de manera paternalista. Con ello se crea una situación de subordinación y supeditación de las personas y de los ciudadanos a las decisiones y a las acciones de quienes representan a los poderes legislativo, ejecutivo y judicial o a una ONG más o menos altruista.

Ante este panorama y tras esta evidencia, algo sucede cuando nuestro imaginario se mueve dentro de unos esquemas que no cuestionan las 
limitaciones de una forma de pensar ni de una manera de entender derechos humanos. Si resulta que nos conformamos con que sean los especialistas en Derecho, los operadores jurídicos y, en último caso, los tribunales de justicia de ámbito nacional o internacional quienes nos digan cuáles son nuestros derechos y, además, resulta que sobredimensionamos y solo nos preocupamos por la etapa o dimensión post-violatoria de los mismos, que queda circunscrita a la esfera de su reivindicación judicial, una vez que han sido ya violados, al final, lo que estamos consolidando es una cultura simplista, deficiente, insuficiente y estrecha de derechos humanos.

Frente a esta concepción excesivamente jurídico-positiva, estatalista, formalista, post-violatoria y delegativa bañada bajo una cultura atomista e individualista, seguidamente vamos a intentar ofrecer, desde la teoría, algunas pistas para una noción más compleja de derechos humanos que procesual, relacional y dinámicamente se construyen a partir de prácticas sociales y acciones humanas que empoderan sujetos y que debe incorporarse en todos los programas y en todas las políticas educativas y de enseñanza ético-cívica. Resulta curioso comprobar cómo se suele argumentar que, para evitar un contenido ideológico y sesgado en los programas de educación en derechos humanos, los gobernantes y los políticos tienen que limitarse a informar a los ciudadanos de cuáles son las normas y los sistemas de garantía que los protegen, junto los antecedentes históricos y la evolución han tenido con el transcurso del tiempo.

A continuación, siguiendo los aportes de Helio Gallardo, decir que derechos humanos tienen como referente básico la vocación de autonomía de los sujetos sociales como matriz de autonomía de los individuos o personas. Guardarían relación con la capacidad que el ser humano tiene y debe tener como sujeto para dotar de carácter a sus propias producciones en entornos que no domina completamente $\mathrm{y}$, también, estarían vinculados con la disposición de denunciar y luchar contra cualquier situación que imposibilite esta capacidad de crear, significar y resignificar a las instituciones socialmente producidas. Para Helio Gallardo, "sujeto" quiere decir ponerse en condiciones sociales e individuales de apropiarse de una existencia a la que se le da carácter o sentido desde otros, con otros, para otros y para sí mismo y de comunicar con autoestima esta experiencia de apropiación. Asimismo, por "autonomía" entiende que 
para los seres humanos resulta posible pasar mediante acciones desde experiencias de menor control (o enajenadoras) a experiencias de mayor control (liberadoras) por parte de quienes las viven en ámbitos étnicos, raciales, libidinales o sexuales, económicos, políticos, de género, etc. El propio Paulo Freire hablaba de concienciar para que cada uno y cada una, tanto individual como colectivamente, se hicieran cargo de sus realidades. Por ello hay que recupera otras dimensiones o elementos de los derechos humanos, como por ejemplo:

- En primer lugar aquel ámbito que da origen a los derechos humanos y los mantiene vivos: la lucha y la acción social. Derechos humanos tienen más que ver con procesos de lucha por abrir y consolidar espacios de libertad y dignidad humanas. En concreto pueden ser concebidos como el conjunto de prácticas sociales, simbólicas, culturales e institucionales que reaccionan contra los excesos de cualquier tipo de poder que impiden a los seres humanos constituirse como sujetos. Los movimientos sociales, a través de la historia, desde racionalidades, imaginarios y demandas distintas, intentan tener control sobre sus entornos entrando en conflicto con otros imaginarios, otras racionalidades y otras reivindicaciones que, por diversas razones, acaban haciéndose hegemónicas. Esto provoca que las luchas no hegemónicas puedan terminar invisibilizadas, silenciadas, eliminadas o resignificadas desde quienes detentan el poder, no obstante las luchas siguen estando ahí y pueden surgir otras nuevas y nuevos movimientos que cuestionen lo oficial e insuficientemente institucionalizado. En el contesto moderno, el problema reside en que solo fue el imaginario burgués el que se impuso al resto de imaginarios (obrero, feminista, libidinal, étnico, ambiental), estableciendo un traje que todos debían colocarse y moldeando una figura a la que los demás debían adaptarse, impidiéndose la posibilidad de construir nuevos trajes y nuevas figuras.

Esta dimensión resulta crucial a la hora de establecer una educación en clave intercultural, pues incorpora el conocimiento de las distintas luchas de resistencia desplegadas por grupos humanos que no solo se circunscriben a los moldes, pautas y ritmos establecidos desde 
la historia de Occidente. Es el caso de los pueblos indígenas y los pueblos afrodescendientes en Latinoamérica, vilipendiados por medio de la esclavitud, el genocidio, el epistemicidio y otros mecanismos de exclusión, marginación, explotación y discriminación.

Son pocos los planes y programas de educación que realmente se preocupen en recuperar la memoria local de cada pueblo indígena, sus dinámicas históricas propias aglutinadas en torno a valores, costumbres y tradiciones que son la base para que su condición de indio sea motivo de autoestima y respeto y no para potenciar sentimientos de vulnerabilidad e infravaloración. ${ }^{7}$

- En segundo lugar, y muy relacionado con lo anterior, para hacer efectivos derechos humanos, las actuaciones humanas y la sensibilidad popular por reconocerlos aluden a una dimensión pre-violatoria de los mismos que nada tiene que ver con la dimensión jurídica y estatal. Por tanto, hay una eficacia no jurídica que tiene mucho que ver con la sensibilidad sociocultural, el grado de aceptación y el modo como derechos humanos son asimilados, significados, resignificados $\mathrm{y}$ entendidos. Por mucho que se reconozcan constitucionalmente los derechos de los pueblos indígenas, si en el entorno social predomina la cultura hegemónica occidental, será muy difícil que exista una sensibilidad por parte de los grupos no indígenas y mestizos hacia sus reclamos. Asimismo, también hay que tener en cuenta que existe una dimensión jurídica no estatal que determinados colectivos - como también ocurre con los pueblos indígenas - utilizan desde lógicas emancipadoras. ${ }^{8}$

- En tercer lugar, resulta decisivo descubrir que, realmente, son nuestras relaciones y prácticas o tramas sociales tanto jurídicas como no jurídicas las que, en cada momento y en todo lugar, nos dan la justa medida de si hacemos o no hacemos derechos

\footnotetext{
7 Ver Marcelo Quishpe Bolaños, op. cit.

8 No vamos a detenernos ahora en las consecuencias limitativas que también tiene el paradigma monista del Derecho. Para una visión desde el pluralismo jurídico, ver Antonio Carlos Wolkmer, Pluralismo jurídico. Fundamentos de una nueva cultura del Derecho, Mad, Sevilla, 2006.
} 
humanos, de si estamos construyendo procesos de relaciones bajo dinámicas de reconocimiento, respeto e inclusión o bajo dinámicas de imperio, dominación y exclusión. En definitiva, si realmente estamos contribuyendo a que los derechos humanos existan o no existan en nuestra cotidianidad. De ahí la necesidad de reflejar permanentemente su dimensión política, sociohistórica, procesual, dinámica, conflictiva, reversible y compleja que tiene que incorporarse en todos los planes o programas nacionales de educación cívica y de derechos humanos. Por tanto, hay que apostar, no por una noción estática y dormida de derechos humanos, sino por una noción sinestésica que nos espabile a todos de la anestesia, con la que los cinco o los seis sentidos actúan simultáneamente las veinticuatro horas del día y en todo lugar. Son prácticas que se desarrollan diariamente, en todo tiempo y en todo lugar y no se reducen a una única dimensión normativa, filosófica o institucional, ni tampoco a un único momento histórico que les da un origen. Derechos humanos guardan más relación con lo que hacemos en nuestras relaciones con nuestros semejantes, ya sea bajo lógicas o dinámicas de emancipación o de dominación, que con lo que nos dicen determinados especialistas lo que son (aunque también repercute en nuestro imaginario y en nuestra sensibilidad sobre derechos humanos). Y así deben enseñarse.

Las dimensiones formal, institucional y doctrinal deben complementarse con el ámbito en el cual son los mismos seres humanos, a través de las tramas sociales que los constituyen como sujetos o como objetos, quienes pueden o no pueden diariamente construir y reconocer derechos de manera solidaria y recíproca, de ahí la clara dimensión política que tienen, además, de la conexión que poseen con la necesidad de que la gente gane poder y lo ejerza emancipadoramente.

Por tanto, la cultura sobre la que se asienta nuestra defensa de los derechos humanos o es mínima o es anestésica o brilla por su ausencia al no potenciar las dimensiones no jurídicas de su articulación, reconocimiento y de respeto previas a su violación (pre-violatorias) y que se desarrollan en todos los espacios sociales (íntimo, doméstico, de producción, de mercado, de ciudadanía, de comunidad, etc.). 
Por estas y otras razones pretendemos destacar y acentuar los límites de esta posición excesivamente normativista y formalista propia de los programa y planes nacionales de educación ciudadana. Si no tenemos claro que son nuestras acciones diarias y cotidianas en todos los ámbitos sociales donde nos movemos las que articulan espacios de reconocimiento de dignidad, siempre adoptaremos una postura demasiado delegatoria y pasiva que reproducirá una efectividad circunscrita, mínima y azarosa de derechos humanos.

Sí hay que aclarar, para no llevar a equívocos, que con esta denuncia no estamos negando la importancia que tienen los ordenamientos jurídicos, los estados constitucionales de Derecho y los sistemas de garantías estatales de los derechos fundamentales, así como su enseñanza. Queda fuera de toda duda la necesidad de defender y educar a partir de las dimensiones filosóficas, juridico-positivas y de eficacia estatal. Son conquistas humanas que hay que consolidar y reforzar, sin caer en eurocentrismos u occidentalismos, pero no son la única y exclusiva forma de garantía contra los diferentes excesos de poder, ni copan la totalidad del contenido a la hora de educar y enseñar derechos humanos. Siendo necesarias, son insuficientes por muchas razones. Está muy claro que hay que mejorar y fortalecer el papel del Derecho y de los sistemas de protección de los derechos humanos tanto a nivel nacional como internacional, así como se hace imprescindible reconocerlos institucionalmente, de ahí la importancia de la educación para la ciudadanía y los derechos humanos, pero no hay que darle el exclusivo y el único protagonismo a esta dimensión normativa. Repetimos: aunque son importantes y necesarias las dimensiones filosófica, institucional y de efectividad jurídico-estatal de los derechos humanos, son insuficientes. Por esta razón hay que ampliar la mirada a otras parcelas y no reducir su enseñanza a estas únicas dimensiones.

No se trata solo de incrementar una conciencia y una cultura jurídica de protección, sino, además, potenciar una cultura de derechos humanos en general, integral y que acentúe la dimensión pre-violadora desde donde se construyen-destruyen y articulan-desarticulan porque, en realidad, somos todos los seres humanos ahí donde nos movemos, quienes, utilizando o 
no utilizando la vía jurídica, participamos en los procesos de construcción o destrucción de derechos humanos, seamos o no seamos juristas.

Cuanto mayor sea esa cultura sobre derechos humanos, menores serán las demandas que tengan que pasar por los tribunales. No es lo mismo promocionar y generar derechos humanos fuera y dentro del ámbito jurídico ya sea como juez o fiscal, abogada, padre, madre, hijo, hija, empresario, empresaria, profesora, médico, portero, taxista, joven, anciano, etc., que considerar, como si fueran hechos consumados, que al no respetarse externamente, en el vivir cotidiano, únicamente pueden garantizarse al interior del mundo del Derecho. Por el contrario, en ambos lugares se hacen y deshacen derechos humanos. Todos programa educativo en ciudadanía debe hacerse cargo y responsabilizarse asumiendo estas otras dimensiones.

\section{Derechos humanos en clave intercultural: hacia una pedagogía pluriversal y de confluencia}

Hasta ahora nos hemos centrado en el problema que existe a partir de una concepción de derechos humanos demasiado simplista, estrecha y reducida, pero no hemos introducido el elemento cultural y vinculado con la universalidad de los mismos. Referirse a los derechos humanos y enseñar derechos humanos puede tener un condicionante muy negativo por su dimensión y carga eurocéntrica. Desde nuestro punto de vista, la idea de derechos humanos oficialmente aceptada y que está más generalizada en la cultura tanto de las personas de la calle, como en el ámbito de los operadores jurídicos y de los teóricos de la academia, no solo provoca cierta indolencia, docilidad y pasividad, además de que consolida la separación, tradicionalmente reconocida, entre la teoría y la práctica, sino que también parte de un imaginario circunscrito a la cultura occidental. Es decir, los derechos humanos son como una especie de traje o vestido, con chaqueta y corbata que se tiene que poner todo el mundo, incluso aquellos hombres y mujeres que no necesitan usarlo porque tienen otra forma de concebir la ropa o porque sus cuerpos o figuras no encajan en ese molde. ${ }^{9}$ Predomina

9 Ver con más detalle, David Sánchez Rubio, Repensar derechos humanos. De la anestesia a la sinestesia, Mad, Sevilla, 2008; y Contra una cultura anestesiada de 
un imaginario excesivamente eurocéntrico y lineal que, aunque posee sus virtualidades y elementos positivos, acaba por implantar una cultura excesivamente anestesiada y circunscrita a una única forma hegemónica de ser humano: la propia desarrollada por Occidente en su trayectoria y versión de la modernidad burguesa y liberal.

Además, sabido es que, históricamente, la mayoría de los estados se han construido bajo la pretensión y el dominio de un grupo nacional dominante. Los estados-nación han surgido fruto de luchas de poder cuyas tendencias se han dirigido hacia la creación de un estado unitario y homogéneo. El colectivo dominante, que podía ser mayoritario o minoritario, según los casos, ha ido utilizando las instituciones estatales para promover su identidad, su lengua, su historia, su cultura, sus mitos, sus símbolos. Para ello se utilizaban políticas de "construcción nacional" tanto de asimilación como de exclusión a expensas de los otros grupos étnicos o indígenas. ${ }^{10} \mathrm{La}$ historia de Occidente está llena de procesos internos y procesos externos de colonización e imperialismo en los que los colectivos o grupos que se resistieron han sufrido represalias políticas, discriminaciones económicas de todo tipo e incluso técnicas de eliminación y destrucción genocida. Esta historia ha ido de la mano del surgimiento y de la posterior universalización del ideal de los derechos humanos. Pese a su componente emancipador, su contexto de desarrollo por el mundo ha tenido también una cara de dominación. Por esta razón son muchas las culturas y los grupos étnicos e indígenas que son recelosos a la hora de utilizar una figura que ha estado asociada a procesos de conquista, robos, pillaje, expolios y guerras. Cuestionan a los derechos humanos como posible instancia universal que permita dar cuenta de todas la expresiones culturales relacionadas con ideales de emancipación, liberación y dignidad humana.

Sea como fuere, cuando hoy se habla de educación en derechos humanos, hay que tener en cuenta estas dimensiones tanto de emancipación como de dominación humanas. Por estas razones una pedagogía o

derechos humanos, Comisión Estatal de Derechos Humanos de San Luis Potosí y Facultad de Derecho de la Universidad Autónoma de San Luis Potosí, 2008.

${ }^{10}$ En este sentido, ver Will Kymlicka, Las odiseas multiculturales. Las nuevas políticas internacionales de la diversidad, Barcelona: Paidós, 2009. 
enseñanza en derechos humanos, debe incorporar el elemento intercultural para evitar seguir participando en la consolidación de discriminaciones y silenciamientos históricos de culturas y grupos humanos cuyos imaginarios, formas de pensar, modos de vida, ritmos y tiempos son muy diferentes al ethos sociocultural de Occidente. Con mayor motivo cuando el actual contexto marcado por la globalización ha ampliado los espacios de intercambio, contacto y sociabilidad pluricultural.

En este sentido, el filósofo canadiense Will Kymlicka da constancia de un incremento en los países occidentales de políticas multiculturales. Existe un mayor número de democracias occidentales que han abandonado el objetivo del ideal de homogeneidad nacional en favor de un Estado más multicultural. Para este autor un Estado de este tipo implica tres ideas básicas: a) rechazar la idea de que el Estado pertenezca a un solo grupo nacional, ya que es patrimonio de todos sus ciudadanos; b) sustituir las políticas asimilacionistas y exclusivistas de construcción nacional por otras de reconocimiento y acomodación; en este caso el Estado tiene el deber de reconocer la historia, la lengua y la cultura de los grupos no dominantes; y c) admitir la injusticia histórica cometida en contra de las minorías y grupos no dominantes a través de estas políticas asimilacionistas y exclusivistas, manifiestando una clara disposición a ofrecer algún tipo de remedio o rectificación. ${ }^{11}$

Aquí resulta necesario establecer un consenso social en aquellos países claramente plurinacionales, muchos de ellos latinoamericanos, sobre cuál es la idea de derechos humanos que se pretende reconocer y enseñar: si se trata de una concepción más o menos liberal, preocupada en los derechos de todos los ciudadanos o en una concepción más abierta a los derechos étnicos y colectivos, haciendo compaginar lo que de común tienen todos los ciudadanos en cuanto tales y lo que de particular tienen determinados grupos con derechos etno-culturales específicos.

Para aclarar un poco sobre las distintas posiciones que se pueden adoptar sobre derechos humanos teniendo en cuenta sus orígenes y las posibilidades de ser compartidos universalmente o por el mayor número de culturas y formas de vida, seguidamente vamos a destacar tres

11 Ídem. 
posiciones y de ellas dependerá el tipo de educación ciudadana que en clave intercultural o multicultural que deseamos señalar: ${ }^{12}$

a) En primer lugar, están aquellas posiciones que defienden que todas las culturas tienen procesos de lucha y versiones sobre la dignidad relacionadas con derechos humanos. Por tanto, todas participan en su proceso de construcción y en cada contexto cultural se debe dar cuenta y hacerse eco de esas distintas luchas y expresiones que, en la mayoría de las ocasiones, se han silenciado, invisibilizado y ocultado.

b) En segundo lugar, como una versión más específica de la anterior, nos encontramos con posturas que afirman que Occidente no creó ni la idea ni el concepto de derechos humanos, sino solo una manera discursiva, filosófica e institucional de sistematizarlos y desarrollarlos, que sin ser exclusiva, se ha hecho hegemónica. Por tanto, cada cultura aporta su granito de arena en el proceso de evolución y desarrollo de los derechos humanos.

c) En tercer lugar, hay quienes consideran que sólo la lucha por la dignidad humana en Occidente ha sido traducida en forma de derechos humanos. Todas las culturas poseen diversas concepciones sobre la dignidad humana, pero no todas ellas las conciben en forma de derechos humanos. Incluso puede haber expresiones de dignidad incompatibles con los derechos humanos. Como posible salida, lo que hay que hacer es buscar los denominadores comunes y las diferencias existentes entre los derechos humanos generados en Occidente y aquellos equivalentes isomórficos vinculados con la dignidad que tienen un parecido estadio o nivel de importancia en las culturas que los defienden.

\footnotetext{
12 Para una mayor profundización véase Jack Donnelly, Derechos Humanos universales: en teoría y en la práctica, Edic. Gernika, México, 1994. Sobre los conceptos de "interculturalidad" y "multiculturalidad", nosotros preferimos hablar de interculturalidad. La interculturalidad denota una dimensión de mayor horizontalidad y equidad entre las culturas que intercambian experiencias de vida. La multiculturalidad, aunque también puede significarse de esta manera, puede estar controlada por una cultura que lleve la voz cantante y establezca cierta hegemonía sobre el resto, adoptando políticas asimilacionistas pese al respeto de la diferencia.
} 
Según cómo se entiendan los derechos humanos, nos encontraremos con expresiones multiculturales diferentes. El pedagogo estadounidense Peter McLaren cuestiona aquellas formas de multiculturalismo, que denomina liberal humanista y liberal de izquierdas, que en base a la igualdad terminan por descaracterizar las diferencias y que en base al respeto de las diferencias terminan por esencializarlas. Para el primer tipo de multiculturalismo, el liberal humanista, se puede hablar de derechos humanos a partir del igualamiento en el reconocimiento de los derechos de todos los miembros de una sociedad, partiendo desde una noción de igualdad natural entre las personas, independientemente de su condición étnica, racial, cultural, sexual, etc. Blancos, afrodescendientes, latinos, indígenas, asiáticos... son iguales. El problema es que, al final, los sujetos se convierten en seres humanos sin atributos y no se atiende a sus especifidades. ${ }^{13}$

En cambio, el multiculturalismo liberal de izquierdas enfatiza tanto la diferencia cultural y los derechos étnicos, raciales, de género, sexuales, etc. que provoca una esencialización de las diferencias como si cada una estuviera predeterminada y naturalizada y no fueran sociohistóricamente producidas y construidas según el poder humano de representar significados. Ignoran los contextos y la situacionalidad espacio-temporal y cultural de las diferencias.

Como alternativa, McLaren propone una pedagogía crítica y de resistencia que nosotros denominamos interculturalidad pluriversal de confluencia, y se basa en una noción de ciudadanía híbrida y solidaria. Utilizando el concepto de "pedagogía de frontera" del pedagogo crítico canadiense Henry Giroux, señala que en el ámbito educativo debe asumirse las diferencias pero sin caer en esencialismos (ya sea en versión anglocéntrica, eurocéntrica, falocéntrica, afrocéntrica o indianocéntrica). Se debe crear una política de construcción de alianzas (p.e. según el lugar, entre poblaciones indígenas, mestizas, etnias, minorías y población mayoritaria) en las que se compartan sueños de emancipación y de solidaridades más allá de posturas paternalistas, asimilacionistas y condescendientes

13 Ver Peter McLaren, Multiculturalismo crítico. $3^{\mathrm{a}}$ edición. Sao Paulo: Cortez Editora, 2000 . 
que para lo único que sirven es para mantener espacios hegemónicos e institucionalizados de incomunicación y de separación racista.

Para esta perspectiva intercultural, a través de los derechos humanos en su versión más universal y abierta a la diferencia, las identidades reconocidas son fronterizas, cambiantes, dinámicas, flexibles y no estáticas, rígidas y cerradas. Además parte de una aceptación de la alteridad cimentada en el intercambio de experiencias, en el contacto y en el enriquecimiento recíproco. Tal como señala Boaventura de Sousa Santos, hay que partir de la premisa de que todas las culturas son incompletas y problemáticas en sus concepciones de dignidad y, además, aceptar que todas ellas poseen versiones intraculturales diferentes, algunas más amplias que otras, algunas con círculos de reciprocidad más amplios que otros, más abiertos en el reconocimiento como sujeto a todos los seres humanos. ${ }^{14}$ Son estas versiones las que deben incorporarse en cualquier programa o plan de educación que pretenda fomentar un espíritu y una actitud realmente intercultural en el reconocimiento de las diferencias.

En este sentido, un conocido proverbio complementado señala que cuando el dedo señala el sol, el tonto mira el dedo. Pero más tonto sería si mirara al sol, pues se quedaría ciego. ${ }^{15}$ Ser tontos o ciegos en políticas educativas sobre derechos humanos vendría a ser el marco dentro del que se mueven quienes defienden tanto una idea de universalidad expansionista y excluyente de los mismos, como una idea de particularidad cerrada e incomunicada que los rechaza a partir de un esencialismo estrecho y blindado. Es por ello que incluso el punto de partida en el que hemos situado al tonto, el marco en el que se encuentra, igualmente está equivocado porque no sólo hay un sol, no sólo hay un dedo y una forma de apuntar al cielo. Hay múltiples soles y estrellas, muchos son los dedos que las señalan e, incluso, hay otras maneras para indicar distintos lugares y sitios. Siempre es muy enriquecedor lo que pueden ofrecernos quienes imaginan y crean diversos mundos, por muy diferentes que sean al nuestro.

\footnotetext{
14 Boaventura de Sousa Santos, A gramática do tempo. Sao Paulo: Cortez Editora, 2006.

15 En Subcomandante Marcos, "Encuentro intergaláctico", Ajoblanco, n 4, 1997.
} 
Esta alternativa pedagógica intercultural de confluencia debe hacerse cargo y debe incorporar en sus programas de enseñanza tanto la presencia de múltiples culturas con sus luchas y reclamaciones, como las distintas visiones y pretensiones de unidad hacia la que aspiran, construidas por medio de las propias relaciones sociales, que pueden ser diferentes y equidistantes unas de otras. De ahí que la idea de derechos humanos y de dignidad humana variará en cada caso. Cada contexto marcará el grado de atención de la diversidad. Pero todo ello hay que hacerlo evitando posturas esencialistas que aparecen tanto en discursos y culturas de carácter localista como globalista y hegemónico. La aceptación de esta pluralidad de opciones no tiene por qué implicar indefectiblemente la total incomunicación y separación entre las culturas. Es cierto que podremos encontrarnos con esferas en las que será imposible establecer vasos comunicantes, pero habrá otras en donde sí serán posibles algunos puntos de encuentro, siendo los derechos humanos uno de esos lugares de confluencia.

Una pedagogía pluriversal debe cultivar el respeto de la diferencia en espacios en los que desde ella permita en igualdad de condiciones a todos los sujetos humanos poder crear, significar, recrear y hacer mundos plurales en lo étnico, lo cultural, lo sexual, lo libidinal, lo social, lo económico, lo político, lo espiritual, lo epistémico y lo espiritual.

\section{Conclusión}

En definitiva, cuando hablamos de derechos humanos, tenemos que saber qué idea tenemos de ellos. Por lo general, existe una cultura oficial y extendida que reduce derechos humanos a valores morales y éticos recogidos en las normas jurídicas y/o constitucionales, a las instituciones que los garantizas y los filósofos y teóricos que reflexionan sobre ellos a lo largo de la historia. Esta visión de derechos humanos provoca cierta pasividad, indolencia y anestesia en los ciudadanos. Además, esta misma concepción reducida es la que se recoge en todos los manuales y programas de educación ciudadana y de derechos humanos.

Para salir de este molde que es excesivamente puntual, formalista y que termina por quitar al ser humano su capacidad de crear y recrear mundos, hay que defender e incorporar en todos los programas educativos 
una perspectiva más compleja que extienda el análisis y la práctica de los derechos humanos a la eficacia no jurídica, la lucha social y la sensibilidad socio-cultural. Derechos humanos guardan relación con las actividades y las tramas sociales socio-históricamente desarrolladas por los seres humanos en todos los lugares sociales.

Asimismo, además de la necesidad de construirse una visión compleja y relacional de derechos humanos, hay que incorporar en ellos la dimensión intercultural dada la fuerte carga eurocéntrica u "occidentalocéntrica" que poseen. Derechos humanos en clave intercultural deben enseñarse teniendo en cuentas las distintas expresiones de lucha por la dignidad humana desarrolladas por cada cultura y/o forma de vida, a partir del respeto de las diferencias y sin caer en esencialismos excluyentes.

\section{Referencias}

CARRILLO GONZÁLEZ, Diana; PATARROYO, Santiago (Ed.). Derecho, interculturalidad y resistencia étnica, Universidad Nacional de Colombia, 2009.

DONNELLY, Jack. Derechos Humanos universales: en teoría y en la práctica. México: Edic. Gernika, 1994.

GALLARDO MARTÍNEZ, Helio. Política y transformación social. Discusión sobre derechos humanos. Quito: Editorial Tierra Nueva, 2000. . Siglo XXI: militar en la izquierda. San José: Arlekín, 2005. . Siglo XXI: producir un mundo. San José: Arlekín, 2006. . Derechos humanos como movimiento social. Ediciones desde abajo, Bogotá, 2006.

HERRERA FLORES, Joaquí. El vuelo de Anteo. Desclée de Brouwer, Bilbao, 2000.

. Los derechos humanos como productos culturales. Crítica del humanismo abstracto. Madrid: Los Libros de la Catarata, 2005.

KYMLICKA, Will. Las odiseas multiculturales. Las nuevas políticas internacionales de la diversidad. Barcelona: Paidós, 2009. 
MARCOS, Subcomandante. Encuentro intergaláctico. Ajoblanco, n. 4, 1997.

MARTÍ, José. Obras Completas. La Habana: Editorial Nacional de Cuba, 1963.

McLAREN, Peter. Multiculturalismo crítico. 3. ed. Sao Paulo: Cortez Editora, 2000.

PECES BARBA, Gregorio. Educación para la ciudadanía y derechos humanos. Madrid: Espasa, 2007.

SÁNCHEZ RUBIO, David (Coord.). Educación para la ciudadanía y derechos humanos. Sevilla: Algaida, 2007.

. El pensamiento humanista de Leopoldo Zea. Conciencia histórica y derechos humanos. Comisión Estatal de Derechos Humanos de San Luis Potosí y Facultad de Derecho de la Universidad Autónoma de San Luis Potosí, 2008.

. Repensar derechos humanos. De la anestesia a la sinestesia.

Sevilla: Mad, 2008.

. Contra una cultura anestesiada de derechos humanos. Comisión Estatal de Derechos Humanos de San Luis Potosí y Facultad de Derecho de la Universidad Autónoma de San Luis Potosí, 2008.

SOUSA SANTOS, Boaventura. A gramática do tempo. Sao Paulo: Cortez Editora, 2006.

WOLKMER, Antonio Carlos. Pluralismo jurídico. Fundamentos de una nueva cultura del Derecho. Sevilla: Mad, 2006.

ZEA, Leopoldo. Dialéctica de la conciencia americana. México D.F.: Alianza Editorial Mexicana, 1974.

. El pensamiento latinoamericano. México D.F.: Ariel, 1976.

Enviado em: 06/2009

Aprovado em:10/2009 